\title{
Síndrome de Boerhaave
}

\author{
Boerhaave's Syndrome
}

\author{
Pedro CABRAL ${ }^{1}$, Pedro JOÃO ${ }^{1}$, Clara ALELUIA ${ }^{1}$ \\ Acta Med Port 2013 Sep-Oct;26(5):622-622
}

Palavras-chave: Pneumomediastino; Perfuração Esofágica/diagnóstico.

Keywords: Mediastinal Emphysema; Esophageal Perforation/diagnosis.

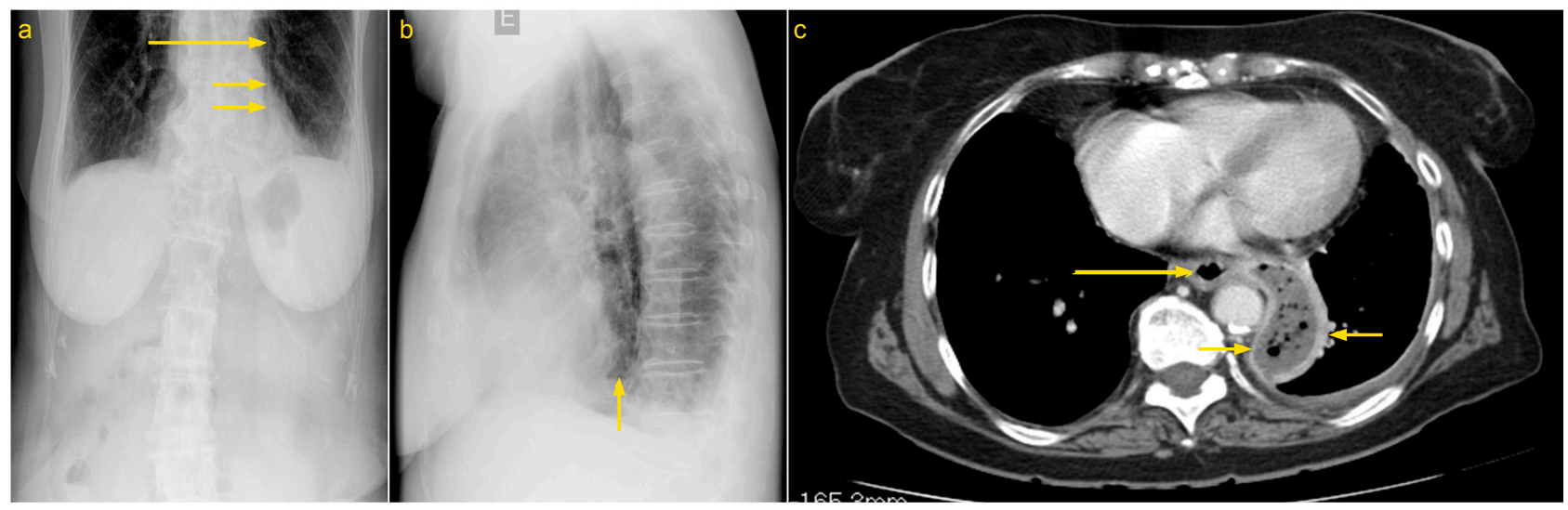

Figura 1 - a) Radiografia do abdómen em pé centrada no diafragma revelou discreta hiperlucência alongada verticalmente na vertente esquerda do mediastino (seta longa), projectando-se sobre a silhueta cardíaca (setas curtas), em relação com pneumomediastino.

b) Radiografia do tórax de perfil com nível hidro-aéreo em topografia retro-cardíaca (seta curta) indicando a presença de pneumoperitoneu complicado com conteúdo de natureza líquida sugerindo ruptura do esófago e abcesso.

c) Tomografia computorizada do tórax com colecção abcedada com conteúdo líquido e gasoso no mediastino (setas curtas), em contacto com a vertente lateral esquerda do $1 / 3$ inferior do esófago (seta longa).

Doente sexo feminino, 52 anos, recorre ao serviço de urgência por dor epigástrica intensa e súbita, com cinco dias de evolução, após episódio de vómitos por gastroenterite aguda. Apresentava exame físico incaracterístico e leucocitose com neutrofilia. A radiografia do abdómen em pé centrada no diafragma revelou pneumomediastino à esquerda, igualmente visível na radiografia do tórax de perfil. A tomografia computorizada do abdómen confirmou o diagnóstico de pneumomediastino, secundário a ruptura do esófago no contexto de síndrome de Boerhaave, complicado com abcesso mediastínico. Foi submetida a reparação cirúrgica com resolução do quadro.

A perfuração do esófago, rara mas potencialmente fatal, pode ser causa de pneumomediastino. ${ }^{1}$ Geralmente é iatrogénica $(55 \%),{ }^{2}$ mas também por ingestão de corpos estranhos, traumática ou espontânea, esta última geralmente associada a vómitos intensos (síndrome de Boerhaave). ${ }^{3}$

É essencial a pesquisa de pneumomediastino nas radiografias pois permite o diagnóstico precoce de situações potencialmente graves em doentes muitas vezes assintomáticos. $^{4}$

\section{REFERÊNCIAS}

1. Khan AZ, Strauss D, Mason RC. Boerhaave's syndrome: Diagnosis and surgical management. Surgeon. 2007;5:39-44.

2. Bladergroen M, Lowe J, Postlethwait R. Diagnosis and recommended management of esophageal perforation and rupture. Ann Thorac Surg. 1986;42:235-9.

3. Sinha R. Naclerio's V sign. Radiology. 2007;245:296-7.

4. Bejvan SM, Godwin JD. Pneumomediastinum: old signs and new signs. AJR Am J Roentgenol. 1996;166:1041-8. 